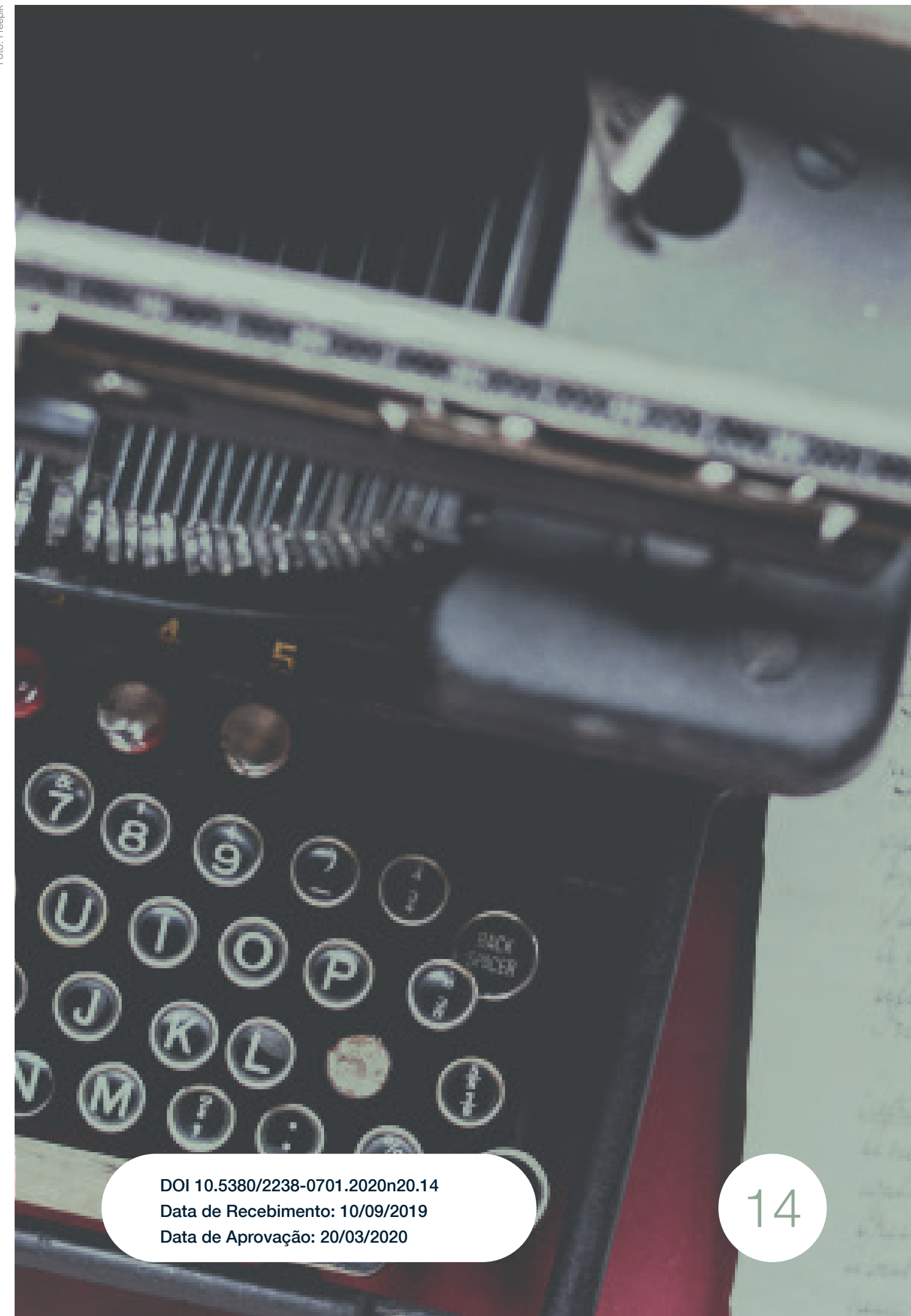


A comunicação soberana em Georges Bataille: o êxtase comunicativo da experiência interior 


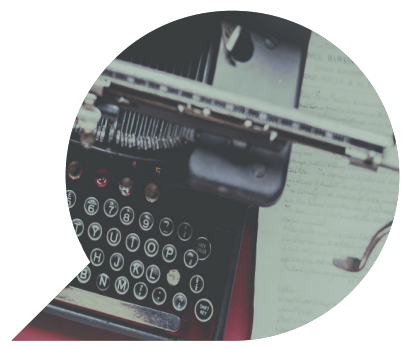

\section{La comunicación soberana en Georges Bataille: el éxtasis comunicativo de la experiencia interior}

A comunicação soberana em Georges Bataille: o êxta-
se comunicativo da experiência interior

Sovereign communication in Georges Bataille: The communicative ecstasy of inner experience

BRAULIO GONZÁLEZ VIDAÑA ${ }^{1}$

ANGÉLICA MENDIETA RAMÍREZ²

Resumen: El pensamiento de Georges Bataille (1897-1962) es considerado fuente de inspiración para diferentes pensadores que constituyen ejes de referencia obligada en la filosofía de la comunicación desde mediados del siglo XX; postestructuralistas franceses como Michel Foucault (1926-1984); Roland Barthes (1915-1980); Jacques Derrida (1930-2004) y Jean Baudrillard (1929-2007), encuentran en Bataille propuestas conceptuales y

1 Doctor en Pensamiento Complejo; Maestro en Ciencias de la Educación, Estudios de Maestría en Ciencia Política y Licenciado en Ciencias Políticas y Administración Pública. Profesor a nivel de educación superior desde el año de 1996. Ha impartido cursos de Teorías de la Comunicación y Comunicación Política desde el año 2002 en diversas instituciones educativas. Es co-autor del libro "La elección no sólo es ni está en las urnas. ¿Y la imaginación política?" publicado en México en junio de 2012 por la editorial LIMUSA.

2 Doctora en Sociología por el Instituto de Ciencias Sociales Alfonso Vélez Pliego de la Benemérita Universidad Autónoma de Puebla. Miembro del Sistema Nacional de Investigadores del CONACYT-México, Nivel I. Autora de más de 25 libros, el más reciente es "La democracia en tiempos de incertidumbre.

El bucle de la comunicación política" publicado en marzo de 2019 por la editorial Gedisa. 
ejercicios de crítica cultural, ineludibles para la comprensión de la sociedad de la comunicación actual. Incluso Jürgen Habermas (1929), en su crítica a la posmodernidad titulada El discurso filosófico de la modernidad (1989), considera a Bataille una de las fuentes básicas para la comprensión de las tesis de Baudrillard, Lyotard y Vattimo. Este artículo traza las líneas generales de la reflexión batailleana sobre la comunicación y su incidencia en la discusión actual sobre los medios.

Palabras clave: Comunicación; Soberanía, Georges Bataille; Posmodernidad; Postestructuralismo.

Resumo: O pensamento de Georges Bataille (1897-1962) tem sido motivo de inspiração para diferentes pensadores que são referência obrigatória na filosofia da comunicação desde meados do século XX; pós-estruturalistas franceses como Michel Foucault (1926-1984); Roland Barthes (1915-1980); Jacques Derrida (19302004) e Jean Baudrillard (1929-2007), encontraram em Bataille abordagens conceituais e exercícios de crítica cultural incontornáveis para o entendimento da atual sociedade da comunicação. Mesmo Jürgen Habermas (1929), na sua crítica do pós-modernismo intitulada O discurso filosófico da modernidade (1989), considera Bataille uma das fontes primordiais para a compreensão das teses de autores como Baudrillard, Lyotard e Vattimo. Este artigo tem o intuito de traçar as linhas gerais da reflexão batailleana sobre a comunicação e salientar as repercussões que têm na discussão contemporânea sobre a mídia.

Palavras-chave: Comunicação; Soberania, Georges Bataille; Posmodernidad; Postestructuralismo.

Abstract: The thought of Georges Bataille (1897-1962) is considered as a source of inspiration for different thinkers who constitute axes of reference obliged in the philosophy of communication since the mid-TWENTIETH century; French poststructuralists like Michel Foucault (1926-1984); Roland Barthes (1915-1980); Jacques Derrida (1930-2004) and Jean Baudrillard (1929-2007), find in Bataille conceptual proposals and exercises of cultural criticism, 
inescapable for the understanding of the current communication society. Even Jürgen Habermas (1929), in his criticism of Postmodernism titled The Modernity Philosophical Discourse (1989) ; it considers Bataille one of the basic sources for the understanding of the theses of Baudrillard, Lyotard and Vattimo. This article traces the general lines of the Batailleana reflection on the communication and its impact on the current discussion on the media.

Keywords: Communication Sovereignty, Georges Bataille; Postmodernity Poststructuralism.

\section{Introducción}

El pensamiento y la obra de Georges Bataille (1897-1962) es una de las aventuras intelectuales más osadas del siglo XX; a la par de Martin Heidegger y Jean Paul Sartre, Bataille es el pensador con mayor trascendencia en las reflexiones filosóficas, literarias, políticas y culturales de la segunda mitad del siglo pasado. Su influencia es evidente y explícita en los programas de investigación y obras creativas de Michel Foucault, Roland Barthes; Jacques Derrida; Maurice Blanchot; Michel Leiris; Julia Kristeva; Phillipe Solers; Jean Baudrillard; Roberto Esposito y Giorgio Agamben entre otros pensadores contemporáneos que han transformado la escena de la filosofía occidental contemporánea.

La vida de Bataille guarda una relación intrínseca con la obra, ya que cada paso de su trayectoria vital se encuentra marcado por una producción literaria y filosófica sugerente, provocadora y especialmente transgresora. Como en su momento lo expresara Foucault a propósito de la noción de transgresión de Bataille:

La transgresión es un gesto que concierne al límite, es allí, en la delgadez de la línea, donde se manifiesta el relámpago de su paso, pero quizás también su trayectoria total, su origen mismo [...] El límite y la transgresión se deben entre sí la densidad de su ser: inexistencia de un límite que no se podrá saltar en absoluto; vanidad a cambio de una transgresión que sólo saltaría por encima de un límite de ilusión o de sombra (FOUCAULT, 2002, p. 34).

La transgresión de los límites teóricos, conceptuales y metodológicos de la ciencia moderna, es parte sustantiva de la crítica del pensamiento 
de Bataille: cada novela, relato, ensayo, epígrafe o fragmento de su obra, conducen a transgredir los límites disciplinarios que fragmentan, reducen y simplifican la complejidad de la experiencia humana.

En el marco de esta intención primordial, Bataille propone experimentar dos componentes clave de la vida humana, la soberanía y la comunicación. A partir de la lectura de su obra La experiencia interior $(2016)^{3}$, primera parte de la llamada por Bataille Suma Ateológica, el autor se introduce en la relación paradójica, dialéctica y contradictoria entre la soberanía de la experiencia mística individual, la animalidad como línea de continuidad del ser con el mundo y la urgencia de comunicar esa vivencia no obstante la fatalidad ineludible de la incomprensión y discontinuidad características de los vínculos humanos.

El presente artículo tiene el objetivo de dilucidar la relación existente entre el concepto de soberanía y el de comunicación con base en la lectura de La experiencia interior (2016), La literatura y el Mal (1977); Teoría de la Religión (1981) y el ensayo de Bataille titulado "Lo que entiendo por soberanía" (1996) que forma parte del volumen VIII de las Obras Completas de Bataille publicado por Gallimard en 1976.

En este orden de ideas, las preguntas que impulsan las reflexiones que a continuación se ensayan son: ¿acaso es comunicable la experiencia interior? ¿la soberanía de la experiencia interior incide en los mecanismos de comunicación? Para responder a estos dos cuestionamientos se organiza el texto en dos grandes apartados, el primero se orienta a estudiar el concepto de soberanía y el segundo analiza la comunicación vista desde el entramado teórico tejido por Bataille.

\section{La soberanía}

La lectura de Bataille permite descubrir en el centro de la soberanía una renuncia, la fuerza de la soberanía moderna es directamente

\footnotetext{
3 Para la realización de este artículo, los autores se basaron en la traducción de este libro realizada por el poeta y filósofo argentino Silvio Mattoni, publicada en el año 2016 por la editorial El Cuenco de Plata de Argentina, la cual incorpora algunas notas de la edición póstuma de la Suma ateológica publicada en 1973 por Gallimard en los volúmenes V y VI de las Obras Completas; en este sentido, cabe señalar que La experiencia interior apareció en 1973, como parte del Volumen V de las Obras Completas. En español fue Fernando Savater el primero en realizar la traducción de La experiencia interior con el sello editorial de Taurus.
} 
proporcional a la renuncia de su propio ejercicio, paradójicamente los revolucionarios que vencieron al monarca y lo decapitaron asumieron al ausente en su propio interior, la soberanía se erige así como la presencia de la ausencia. La noción de soberanía es una de las categorías más importantes en el proyecto filosófico de Georges Bataille, en su acepción habitual es un atributo del depositario del poder. En el empleo que de la soberanía hace Bataille la aleja de su contenido jurídico que no aparecerá más que indirectamente en el sentido de que actuar soberanamente es no someterse a las normas sociales (BATAILLE, 1996).

La reflexión de Bataille sobre este punto desarrollada en su obra póstuma La soberanía ${ }^{4}$, retoma el enfoque hegeliano de la dialéctica del amo y el esclavo propuesta por Hegel en la Fenomenología del Espíritu (2017); con base en la toma de conciencia de sí mismo del sujeto, en virtud de la posición que ocupa en la relación con los demás. Los otros, la alteridad radical a la que se enfrenta la conciencia de sí, conduce -en el marco del proceso dialéctico-, a una conciencia para sí, la cual es un nosotros que nace de la contradicción esencial entre el yo del amo y el yo del esclavo 5 .

Lo interesante de esta reflexión hegeliana que retoma Bataille -bajo la lectura de Alexander Kojéve (1902-1968)- es que la conciencia de sí es vista como una autoconciencia deseante, en donde el Yo se constituye por el deseo, así lo enuncia Kojéve:

Es el Deseo el que transforma al Ser revelado a él mismo por él mismo en el conocimiento (verdadero), en un «objeto» revelado a un «sujeto» por un sujeto diferente del objeto y «opuesto» a él. Es en y por, o mejor aún, en tanto que «su» Deseo que el hombre se constituye y se revela -a sí mismo y a los otros- como un Yo, como el Yo esencialmente diferente del no-Yo y radicalmente opuesto a éste. El Yo (humano) es el Yo de un Deseo o del Deseo (KOJÉVE, 1982, p. 1).

\footnotetext{
4 La obra no fue concluida por Bataille, sin embargo la editorial Gallimard la incorpora en el Volumen VIII de las Obras Completas de Bataille, publicadas en el año de 1976. El ensayo "Lo que entiendo por soberanía" es la introducción teórica que el autor escribió para lo que sería el libro La soberanía, el cual constituye la tercera parte de una segunda trilogía a la que Bataille llamaría "La parte maldita" y que se completa con los libros La parte maldita y El erotismo publicados en vida del autor. Es importante subrayar que la primera trilogía fue la Suma ateológica, compuesta por La experiencia interior; El culpable y Sobre Nietzsche.

5 Es importante señalar que la lectura de Hegel que hace Bataille, es producto de los cursos que impartió en París el filósofo ruso Alexander Kojéve (1902-1968) de 1933 a 1939, cursos a los que asistió Bataille junto con otros destacados intelectuales de la época como Jacques Lacan (existe traducción al español con el mismo título publicada por la editorial La pléyade en el año de 1982: La dialéctica del amo y del esclavo en Hegel).
} 
Y es con base en el deseo como Bataille construye su propuesta de soberanía con la que se expresa la posibilidad última de la experiencia en el mundo y de la apertura del ser como autoconciencia deseante, a las autoconciencias deseantes de los demás. Imposibilidad y paradoja que implica una nueva desgarradura, ya no desde la conciencia del entendimiento, sino desde la experiencia del deseo que es el combustible de la soberanía al decir de Bataille (BATAILLE, 1996).

El autor de La experiencia interior comienza su análisis buscando abarcar los espacios dejados vacíos por Hegel. La soberanía es estudiada por Bataille en principio como una categoría político-social puesta sobre un individuo de rango superior. Solamente con violencia se ha podido trasladar, en el espíritu de la revolución, a su ambigua aplicación colectiva, afirmando que la soberanía reside en el pueblo, dado que no puede ejercerla, pues siempre ha de hacerlo a través de otros en los que la delega lo que, estrictamente hablando, equivale a no ejercerla (BATAILLE, 1996).

Bataille sitúa la soberanía en la acción de un individuo que metafóricamente equivale a la de un soberano, por supuesto, es una equivalencia formal que el pensador francés produce para fortalecer el sentido inconmensurable de la soberanía. La acción propiamente soberana es la acción desprovista de acicate de la necesidad y la conveniencia; se liga sólo al instante, es ajena a toda expectativa del porvenir; es la pura expresión de un deseo caprichoso y espontáneo, que no responde a un cálculo de consecuencias, y que, en general, implica la destrucción de bienes, el mal o la muerte (BATAILLE, 1996).

La acción soberana es, entonces, lo opuesto a la acción servil, consistente en supeditar el presente al futuro, que es también la acción racional propia del trabajo, la moral y la obediencia a la ley, que están unidas por este modo de valorar el tiempo y su influencia sobre la acción. Lo soberano es lo contrario a la producción, es, pues, la destrucción de bienes, el gasto improductivo del erotismo, del juego, de la muerte, del arte y la literatura (BATAILLE, 1996).

Lo que distingue a la soberanía es el consumo de riquezas, en oposición al trabajo, a la servidumbre, que producen las riquezas sin consumirlas. El soberano consume y no trabaja, mientras que, en las antípodas de la soberanía, el esclavo, el hombre sin recursos, trabajan y reducen su consumo a lo necesario, a los productos sin los cuales no podrían subsistir ni trabajar (BATAILLE, 1996, p. 64) 
El intento de Bataille, arroja luz sobre la paradoja de la soberanía, la revela, pero no la resuelve; sin embargo, lo que se gana en ello es hacer patente el rostro huidizo de la soberanía en la que el rey se divide en dos partes, una que impone la ley y otra que se tiene que sujetar a la norma. Es la paradoja que Giorgio Agamben pone al desnudo en el portal de su brillante texto Homo Sacer. El poder soberano y la nuda vida (1998):

La paradoja de la soberanía se enuncia así: ‘El soberano está, al mismo tiempo, fuera y dentro del ordenamiento jurídico. La precisión 'al mismo tiempo' no es trivial: el soberano, al tener el poder legal de suspender la validez de la ley, se sitúa legalmente fuera de ella. Y esto significa que la paradoja de la soberanía puede formularse también de esta forma: 'Yo el soberano que estoy fuera de la ley, declaro que no hay un afuera de la ley (AGAMBEN, 1998, p. 27).

\section{Comunicación soberana}

A contracorriente de Hegel, pero en una línea que se pinta con motivos hegelianos, Georges Bataille estructura un sistema inacabado del no saber que parodia en el espejo, los anhelos sistematizadores de la razón. Para Bataille, la tarea del pensar es abrirse a la insubordinación constante frente al dominio de lo necesario y su utilidad, con el propósito declarado de hacer un recorrido por las diversas experiencias del hombre desde la inmanencia del animal devorador o devorado, hasta el mundo de la razón como guerra y orden industrial (BATAILLE, 2016).

Bataille escribe su Teoría de la Religión en el que se perfila el fundamento su idea de comunicación. Ahí, analiza la animalidad, el sacrificio, el orden militar, la moral, la mediación y el desarrollo industrial como momentos del tránsito de la continuidad animal primigenia hacia la discontinuidad del mundo del trabajo productivo (BATAILLE, 1981).

En este sentido, para Bataille la animalidad es un estado de inmediatez y continuidad con el mundo, es un estado de indistinción que permite plantear la situación fundamental: “... todo animal está en el mundo como el agua dentro del agua" (BATAILLE, 1981, p. 27).

En esta circunstancia ser devorado o devorar a otro, no es el resultado de una relación objetual del amo y el esclavo, sino que deviene como expresión de una fuerza mayor pero no reconocida por las partes, en ese 
instante sólo se experimenta el eterno presente de un mundo marcado por la duración aprehensible del otro. Recordemos que para Hegel el tránsito de la certeza sensible inmediata al entendimiento como distinción y separación de la generalidad se produce a través de la escisión entre el sujeto y el objeto. De este modo, la inmanencia de la animalidad se desliza sobre la pátina de la historia en la realización del ser como tiempo y objeto que se cosifica en el concepto que el propio entendimiento acuña (BATAILLE, 1981).

En Bataille los impulsos de la animalidad, mirados por medio del cristal de la transgresión, constituyen el agujón arcaico e informe de la humanidad, ya que la profundidad abismal del animal es la nuestra:

El animal abre ante mí una profundidad que me atrae y que me es familiar. Esa profundidad en cierto sentido la conozco: es la mía. Es también lo que me es más lejanamente escamoteado, lo que merece ese nombre de profundidad que quiere decir con precisión lo que me escapa (BATAILLE, 1981, p. 26).

Esta es una lúcida revelación que Bataille asume como el imposible poético de toda comunicación profunda e íntima. Mientras que Hegel sucumbe a la tentación de abandonar el deslumbramiento de la conciencia que provoca la poesía del despliegue del saber, para seguir la claridad de una conciencia que se estructura a sí misma como para sí, a partir de una comunidad de razón, Bataille se propone la inmersión en la inmediatiez e inmanencia de la noche animal que no miente. Sin embargo, aún queda la experiencia del límite desde la cual adquiere sentido cualquier acción soberana:

Sólo en los límites de lo humano aparece la trascendencia de las cosas con relación a la conciencia... Inevitablemente, ante nuestros ojos, el animal está en el mundo como el agua en el agua (BATAILLE, 1981, p. 27).

El animal representa una continuidad indiscernible en donde la única distinción se establece entre el estar vivo o estar muerto. Aquí no hay triunfo ni gloria, no hay derrotados y vencidos, sólo un animal cuya existencia se vio obstaculizada por otro y por medio de la fuerza y el combate mortal, elimina la alteridad del oponente y, al hacerlo, se muestra que el signo de su vida es igual al mundo en el que transita (BATAILLE, 1981).

Para Bataille la soberanía y la comunicación son una y la misma cosa, ya que lo que distingue al hombre del animal es la posibilidad de 
experimentar la indiferencia frente a la muerte, con la lucidez de saber que se está trasponiendo el umbral de una norma o principio que limita, que separa, en suma que incomunica a los hombres en el estado de discontinuidad, sólo en la continuidad que abre el mal como transgresión soberana del límite se posibilita la comunicación soberana. En su ensayo La literatura y el mal (1977), el bibliotecario6 parisino lo afirma categóricamente:

No hay diferencia alguna entre la comunicación fuerte representada de este modo y lo que yo entiendo por soberanía. La comunicación; es, en intención, comunicable: si no, no es soberana. Hay que decir, insistiendo en ello, que la soberanía es siempre comunicación, y que la comunicación, en el sentido pleno, es siempre soberana (BATAILLE, 1977, p. 148).

La humanidad se diferencia de la animalidad justo por la observación de determinadas normas o tabús, por ejemplo: el incesto, la sangre menstrual, la obscenidad, el asesinato o el comer carne humana. En Bataille la comunicación o la soberanía se gestan en el marco de las prohibiciones comunes en donde:

La vía de creación de un elemento soberano (o sagrado) es una negación de esas prohibiciones cuya observación general nos hace seres humanos y no animales. Esto quiere decir que la soberanía, en la medida en que la humanidad se esfuerza por lograrla, nos exige situarnos por encima de la esencia que la constituye. Esto quiere decir que la comunicación primordial sólo puede hacerse con una condición: que recurramos al Mal, es decir, a la violación de la prohibición (BATAILLE, 1977, p. 148-149).

Recurrir al Mal como existencia soberana, es un primer paso que se consuma sólo en la comunicación, de otro modo se agota en el simple corrimiento de los límites como bien lo dedujo Foucault (2002) en su análisis del concepto de transgresión de Bataille. De ahí que para Bataille existan dos tipos de comunicación: la comunicación débil, base de la sociedad profana (que es la sociedad activa y productiva) y la comunicación fuerte, que abandona a las conciencias que se reflejan una a otra a ese algo impenetrable que es el dato simple de la animalidad revelada en la multiplicidad de las conciencias transgresoras y en su comunicabilidad. La actividad habitual nos separa de los momentos sagrados de la comunicación fuerte que fundamentan: “... las emociones de la sensua-

6 Bataille trabajó toda su vida como especialista en numismática en la Biblioteca Nacional de París. 
lidad y de las fiestas, que fundamental el drama, el amor, la separación y la muerte" (BATAILLE, 1977, p. 147).

Y ¿cuál es el medio en que se comunica esta experiencia? El escándalo, Bataille afirma al respecto que el escándalo es el hecho instantáneo de que una conciencia sea conciencia de otra conciencia, sea mirada de otra mirada y de este modo: "... es fulguración íntima, que se aleja de lo que habitualmente vincula a la conciencia con la inteligibilidad duradera y tranquilizadora de los objetos" (BATAILLE, 1977, p. 147).

El escándalo es una trampa sin duda, pero que evita el desgarramiento de la soledad, mantenemos -dice Bataille- con el escándalo que a toda costa queremos provocar -pero del que contradictoriamente intentamos escapar- un lazo indefectible, pero deseamos sea lo menos doloroso posible, bajo la forma de arte o religión:

Este esfuerzo incesante que tiende a situarnos en el mundo de una manera clara y distinta sería aparentemente imposible si no estuviéramos previamente unidos por el sentimiento de la subjetividad común, impenetrable para sí misma, y para la que es impenetrable el mundo de los objetos distintos (BATAILLE, 1977, p. 146).

Esa subjetividad común de la que habla Bataille, se revela en dos momentos extáticos de la experiencia humana: la muerte y el erotismo; los dos rostros de Jano con los que se articula la posibilidad misma de comunicar, de ser con el otro y de abrir la discontinuidad fracasada de una noción de subetividad fraguada desde la modernidad racionalista, como una subjetividad de "ideas claras y distintas" que reducen la complejidad de la experiencia humana en el mundo y su profundo potencial de comunicación gracias a esa realidad esencial que nos articula y comunica: nuestro ser para la muerte y nuestro deseo de continuidad erótica.

La soberanía como la comunicación, no es un objeto que se pueda poseer, es una vía de búsqueda constante de la subjetividad comunicada de forma incesante en la risa, el espasmo del amor, el goce extático de lo sagrado y la creación fulgurante del arte:

...la humanidad no está hecha de seres aislados, sino de una comunicación entre ellos; jamás estamos dados, ni siquiera a nosotros mismos, si no es en una red de comunicaciones con los demás: estamos inmersos en la comunicación, estamos reducidos a esta comunicación incesante, cuya ausencia experimentamos hasta en el fondo de la soledad, como sugestión de múltiples posibilidades, como la espera de un momento en que se resuelva en un grito 
que los demás escuchan. Porque la existencia humana no es en nosotros, en esos puntos en que periódicamente se anuda, más lenguaje gritado, espasmo cruel, risa loca, en donde nace el acuerdo de una conciencia -al fin compartida- de la impenetrabilidad de nosotros mismos y el mundo (BATAILLE, 1977, p. 137).

La comunicación en el sentido en que Bataille la entiende, nunca es efectivamente mayor que en el momento en que la comunicación se muestra vana y similar a la noche, de ahí el poder secreto del escándalo en el que la conciencia de ser es el escándalo de la conciencia, donde una conciencia sin escándalo es una conciencia alienada, una conciencia de objetos claros y distintos, inteligibles o por lo menos creídos como tales.

La soberanía sólo es posible en la supresión del ser aislado, es en la continuidad del arte literario o del éxtasis amatorio en donde se expresa la lucidez soberana del creador y del lector, ambos creando una comunidad imposible de mutuas negaciones, supresión del autor en su obra y supresión del lector en la lectura, lo único que perdura en esta desaparición es el Verbo. La comunicación es lo contrario de la cosa, que se define por el aislamiento que es posible realizar con ella (BATAILLE, 1977, p. 138).

Esta negación a toda cosificación de la experiencia humana de la comunicación es el núcleo de la reflexión batailleana en torno a la experiencia interior como detonante de procesos de comunicación fuerte que quiebran el ciclo de reproducción técnica de la comunicación. En La experiencia interior (2016) define lo siguiente:

Entiendo por experiencia interior lo que habitualmente se llama experiencia mística: los estados de éxtasis, de arrebato, cuanto menos de emoción meditada. Pero pienso menos en la experiencia confesional, a la cual debieron atenerse hasta ahora, que en una experiencia desnuda, libre de ataduras, incluso de origen, con cualquier tipo de confesión (BATAILLE, 2016, p. 25).

Es decir, que la experiencia interior, puede ser un éxtasis capaz de sacar de su centro a cualquier entendimiento racional, a partir de arrebatos que no se ligan a ningún dogma religioso o confesión eclesiástica instituida. De ahí el potencial generador de comunicación que la experiencia interior posee en un entorno incierto de subjetividades puestas a prueba en todas sus certezas racionales. Bataille sostiene que la experiencia interior responde a la necesidad de "objetar todo (de cuestionar) sin tregua admisible" (Bataille, 2016, p. 255). Es por eso que el punto de 
partida de esta experiencia es el no-saber:

Quise que el no-saber fuera su principio -en lo cual seguí con un rigor más duro un método en el que sobresalieron los cristianos... Pero esa experiencia surgida del no-saber permanece decididamente allí... La experiencia es la puesta en cuestión (a prueba), en la fiebre y la angustia, de lo que un hombre sabe por el hecho de ser (BATAILLE, 2016, p. 25).

En La experiencia interior (2016), Bataille dedica un capítulo al problema de la comunicación, ahí el autor parte de la siguiente idea:

Más profundamente, tu vida no se limita a ese inasible flujo interior; se vierte también hacia afuera y se abre incesantemente a lo que se derrama o brota hacia ella. El torbellino duradero que te compone choca con torbellinos similares con los cuales forma una vasta figura animada por una agitación regulada. Pero vivir significa para ti... los pasajes de calor o de luz de un ser a otro, de ti a tu semejante o de tu semejante a ti (aun en el instante que me lees, te afecta el contagio de mi fiebre): las palabras, los libros, los monumentos, los símbolos, las risas no son sino otros caminos de ese contagio, de esos pasajes (BATAILLE, 2016, p. 122).

De esta manera, la comunicación se abre paso desde una solidez vacía y estable, hacia la abertura del ser a la risa, al calor de los demás y a la luz de sus imágenes que se adquieren por contagio, por roces casi epidérmicos que articulan la piel simbólica con la que una sociedad se cubre:

Cada existencia aislada sale de sí misma en beneficio de la imagen que trasluce el error del aislamiento fijado. Sale de sí misma en una especie de estallido fácil, y al mismo tiempo se abre al contagio de un oleaje que se reitera, porque los reidores se juntan como las olas del mar, ya no existe una barrera entre ellos mientras dure la risa... (BATAILLE, 2016, p. 123).

La risa, el éxtasis y el rompimiento de los límites, en otras palabras, la transgresión, es lo que hace posible la comunicación. Dicho de otro modo, comunicar es transgredir el límite del discurso, quebrar el "orden del discurso" (Foucault dixit), en un vertiginoso juego de signos que se mueven a gran velocidad como fuerzas desbordantes de un ser que en su iluminación desde el no-saber de la experiencia interior, inaugura nuevas expresiones de si mismo desde la otredad radical del éxtasis vuelto interioridad expuesta, carne al aire, erotismo del pensamiento y fenomenología de los cuerpos. 
Se trata en suma, de la paradójica continuidad inefable de los seres discontinuos, como en la Teoría de la Religión (1981) lo vislumbrara Bataille: "agua en el agua", animalidad radical que se hace una con el tiempo y con el trasiego del deseo que, en su transitar incansable por el río del ser, comunica lo imposible: la radical soledad del culpable.

\section{Reflexión final}

La obra de Georges Bataille engendra conceptos que alimentan la crítica postestructuralista de la filosofía occidental; sus conceptos, transgresión, experiencia interior, animalidad, comunicación fuerte y éxtasis, contribuyen a situar los ejes de la discusión actual en torno al papel de la comunicación mediada por las nuevas tecnologías de la información.

Seguramente a eso se refiere el "éxtasis de la comunicación" del que hablaba Baudrillard cuando fundamentaba su noción de simulacro: la sustitución paródica de lo real por los signos de lo real. O quizás, la sonrisa de Bataille también se encuentre en algunas de las provocaciones de Byung-Chul Han cuando al hablar del narcisismo de la era actual afirma que "el hombre actual permanece igual a sí mismo y busca en el otro tan solo la confirmación de sí mismo" (BYUNG-CHUL, 2014, p. 33).

Cabría realizar un análisis genealógico del pensamiento de Bataille y su presencia en pensadores como Barthes, Foucault, Derrida, Baudrillard y otros más contemporáneos como Jean Luc-Nancy; Giorgio Agamben o Roberto Esposito. Esto permitiría trazar las líneas de continuidad y las rupturas entre Bataille y la filosofía de la comunicación actual. En especial, la realización de un estudio de esta naturaleza, permitiría recuperar la vertiente crítica de un pensador que hizo de la experiencia interior una posibilidad real para la soberanía de la comunicación. 


\section{REFERENCIAS}

AGAMBEN, G. Homo Sacer. El poder soberano y la nuda vida. Valencia: Pre-Textos, 1998.

BATAILLE, G.. La souveraineté. CEuvres Complétes VIII. Paris: Gallimard. pp. 247-456, 1976

BATAILLE, G. La literatura y el mal. Madrid: Taurus, 1977.

BATAILLE, G. Teoría de la religión. Madrid: Taurus, 1981.

BATAILLE, G. Lo que entiendo por soberanía. (con ensayo introductorio de Antonio Campillo). Barcelona: Paidós, 1996.

BATAILLE, G. La experiencia interior: suma ateológica I. (Prólogo y traducción de Silvio Mattoni). Buenos Aires: El cuenco de plata, 2016.

BYUNG-CHUL, H. La agonía de eros. Barcelona: Herder, 2014.

FOUCAULT, M. "Prefacio a la transgresión" en Sigg, P. y Villegas, G. (editores) (2002). Georges BataiIle: meditaciones nietzscheanas. México: Universidad Autónoma Metropolitana-Universidad Nacional Autónoma de México y Fondo Nacional para la Cultura y las Artes, 2002.

HABERMAS, J. El discurso filosófico de la modernidad. Madrid: Taurus, 1989.

HEGEL, G. W. F. Fenomenología del espíritu. (Segunda edición en español, a partir de una nueva traducción basada en la edición histórico-crítica de las Gesammelte Werke de Hegel, realizada por Gustavo Leyva a partir de la traducción de 1966 de Wenceslao Roces y Ricardo Guerra). México: Fondo de Cultura Económica, 2017.

Data de recebimento: 10 setembro 2019

Data de aprovação: 20 março 2020 


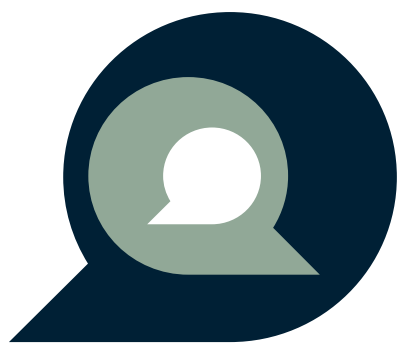

